\title{
Acerca de un posible sentido secular del perdón
}

\author{
On a secular sense of forgiveness
}

\author{
Pedro RIVAS \\ Universidad Austral (Buenos Aires, Argentina) \\ pedro.rivas@udc.es
}

RECIBIDO: 02/11/2019/ ACEPTADO: 14/01/2020

\begin{abstract}
Resumen: En el ámbito de los procesos de transición política hacia la democracia ha jugado un papel relevante la posibilidad de introducir algún género de petición y otorgamiento del perdón como dimensión de la reparación y la reconciliación. Este trabajo se pregunta si nuestra visión común del perdón es una herencia exclusivamente cristiana. Para ello, considera el lugar del perdón, si es que tuvo alguno, en la tradición filosófica clásica griega y latina. En segundo lugar, se trata de buscar un concepto secular del perdón posterior a la aparición del cristianismo. A diferencia del concepto precristiano, en este caso hará falta encontrar no sólo alguien que lo haya formulado, sino que además lo haya hecho con caracteres diferentes al sentido cristiano del perdón.
\end{abstract}

Palabras clave: Perdón. Justicia Transicional

\begin{abstract}
The possibility of introducing some kind of request and grant of forgiveness as a dimension of reparation and reconciliation has played a relevant role in the processes of political transition towards democracy. This paper deals with our common vision of forgiveness as an exclusively Christian heritage. To do this, it considers the place of forgiveness, if any, in the classical Greek and Latin philosophical tradition. Second, it is about seeking a secular concept of forgiveness after the appearance of Christianity. Unlike the pre-Christian concept, in this case it will be necessary to find not only someone who has formulated it, but also has done so with characters other than the Christian sense of forgiveness.
\end{abstract}

Keywords: Forgiveness. Transitional Justice.

Sumario: 1. VERSIONES CLÁSICAS DEL PERDÓN. 2. VERSIONES CONTEMPORÁNEAS DEL PERDÓN.

E

n el ámbito de los procesos de transición política hacia la democracia se ponen en juego aspectos relevantes para la Filosofía jurídica y la Filosofía política. Se trata de momentos históricos que son clave para la conciencia de sí que tiene una comunidad política. Como fruto de la experiencia de diferentes procesos de transición política se han elaborado a nivel internacional un conjunto de principios de la denominada justicia de transición o justicia transicional. En la elaboración de tales principios y, en primer lugar, en el desarrollo de los procesos más característicos ha jugado un papel relevante la posibilidad de introducir algún género de petición y otorgamiento del perdón como dimensión de la reparación y la reconciliación a que todo proceso de transición aspira. Evidentemente, se trata de una cuestión altamente conflictiva. Entonces, ¿por qué se introducen la reconciliación y el perdón en los procesos de justicia transicional? 
En realidad, parece que la reconciliación y el perdón son elementos importantes, fines que más o menos debe buscar una sociedad que ha padecido en su seno esas graves violaciones de derechos humanos. Incluso parece que quienes, como los partidos políticos, los buscan por interés y sólo en determinadas ocasiones, reconocen en esas ocasiones su valor y su necesidad. Ahora bien, ¿por qué hay que perdonar? Si es algo sobre lo que sólo las víctimas pueden decidir, ¿qué razón general hay para perdonar y para considerar por tanto valioso el perdón? En la respuesta a esta pregunta no podemos echar mano de nuestros consensos morales característicos de las sociedades occidentales contemporáneas. Me refiero en definitiva a los derechos humanos. $\mathrm{Y}$ es que no parece que exista ningún derecho a perdonar ni a ser perdonado. No hay exigencias ni imperativos morales o jurídicos deducibles a partir de ese conjunto de derechos. ¿Qué razones tenemos entonces para perdonar? O dicho de otro modo, ¿por qué perdonamos? La respuesta que explica el perdón en el ámbito de las relaciones de intimidad (como, por ejemplo, las familiares) no sirve. En esos casos advertimos que esa intimidad tiene que ver con el amor y éste explicaría el perdón. Pero estamos precisamente en un ámbito diferente, casi el que tendemos a presentar como opuesto al familiar. ¿Qué sentido tiene perdonar? Ante la pregunta uno empieza a sospechar que en este punto (juzgue cada uno en este momento si para bien o para mal), todos los occidentales seguimos siendo cristianos. Porque no se acierta a primera vista a encontrar otra razón de la insistencia en comprender el perdón como un bien. Y aquí aparece la segunda perplejidad anunciada. Porque a fin de cuentas, ¿no habíamos expulsado la religión de la vida pública? ¿No se trata de algo propio exclusivamente del ámbito de la intimidad? Aún más, ¿no es más bien en el momento presente la raíz de muchos conflictos en el mundo al punto de que algunos la consideran como una amenaza? ¿O, tal vez, simplemente resulta que no nos tomamos demasiado en serio nuestro empeño de ser una sociedad post-religiosa y secularizada? Más allá de nuestra manifiesta tendencia contemporánea a no tomarnos demasiado en serio, ¿tiene sentido hablar de perdón al margen de lo religioso? ¿Tiene otro fundamento más acá que el de una creencia religiosa? ¿Podemos justificar su entrega o su denegación con razones morales universales? ¿O estamos ante una realidad que tal y como la entendemos y practicamos es una herencia cristiana y nada más? En definitiva, se trataría de un elemento que forma parte de unas prácticas y de una visión de la realidad que asumimos acríticamente como parte de la comprensión común de la conducta humana, porque se nos ha entregado así y porque no vemos a nuestro alrededor nada que parezca contradecirla y menos aún que sea capaz de construir una visión alternativa. 
Para tratar de responder a todas esas preguntas se debe comprobar en primer lugar qué comprensión del perdón había en Occidente antes de la aparición del cristianismo para comprobar si, en efecto, nuestra visión común del perdón es una herencia exclusivamente cristiana. Un trabajo histórico de ese calibre excede estas páginas. Pero no resulta difícil observar al menos el lugar del perdón, si es que tuvo alguno, en la tradición filosófica clásica griega y latina. Si nuestro imaginario actual sobre el perdón tiene raíces en esa tradición, podremos afirmar que hubo un concepto secular anterior al cristianismo que explicaría, al menos en parte, nuestra querencia presente por el perdón. Ahora bien, si el cristianismo transformó Occidente al punto de unificar durante siglos la comprensión del mundo, parece evidente que en el momento presente hay rasgos de la cosmovisión cristiana que han dejado de ser comunes. Cómo se le quiera llamar a este cambio, cuáles sean sus causas, qué rasgos han cambiado y con qué intensidad, qué valoración merece dicho cambio, etc., son preguntas ajenas a estas páginas. Lo que hay que preguntarse es si el perdón es uno de esos rasgos que ha sufrido transformación y en qué medida. Dicho de otro modo, se trata de buscar un concepto secular del perdón posterior a la aparición del cristianismo. A diferencia del concepto precristiano, en este caso hará falta encontrar no sólo alguien que lo haya formulado, sino que además lo haya hecho con caracteres diferentes al sentido cristiano del perdón. A responder a estas cuestiones se dedica este trabajo.

\section{VERSIONES CLÁSICAS DEL PERDÓN}

$\mathrm{Al}$ aproximarse a un fenómeno como el del perdón, cualquier mentalidad contemporánea no puede evitar la intuición de que estamos ante una realidad donde lo definitivo pertenece al ámbito de lo religioso, en particular y desde un punto de vista occidental al del cristianismo. Por eso, para una mentalidad occidental y desde una perspectiva puramente filosófica, resultaría de gran utilidad poseer algún estudio que se hiciera cargo de forma completa de los sentidos paganos del perdón en la Antigüedad clásica. Una monografía relativamente reciente sobre el tema comienza afirmando que tal estudio no existe más allá de algún trabajo sectorial sobre la cuestión ${ }^{1}$. Sin pretender hacer

1 Cfr. Ch. L. GRIswold, Forgiveness. A Philosophical Exploration, New York, Cambridge University Press, 2007, p. 1. 
un catálogo exhaustivo de todas las menciones al perdón y a otros términos asociados, a mi juicio, resulta posible detenerse en algunos pensadores fundamentales para arrojar algo de luz sobre la perspectiva del perdón previa al cristianismo.

En primer lugar podemos buscar en la tradición griega anterior a Sócrates. Allí, el modo tan distinto de concebir las acciones del hombre con respecto a nuestro presente histórico hace que no podamos encontrar una referencia válida $^{2}$. Y será suficiente reparar en tres asuntos: el papel de la libertad, el alcance de la responsabilidad y los parámetros del juicio sobre la moralidad de las acciones. Empezando por la cuestión de la libertad, se observa la presencia de dos factores que condicionan su valor: la constante presencia del destino y la actividad de los dioses. En lo referente a la responsabilidad por los actos propios, los personajes de los escritos homéricos y de la tradición literaria posterior son considerados responsables de todas sus acciones, incluso de aquellas que han sido hechas bajo posesión divina o estados de inadvertencia por otra causa.

Como consecuencia de esta peculiar relación entre la libertad y la responsabilidad se deduce que la moralidad recae de modo exclusivo en el contenido material de las acciones. Lo que se juzga es cada acto considerado de modo desligado de quién sea su causa, qué intenciones le mueven, qué circunstancias confluyen en su decisión. Las intenciones del sujeto carecen totalmente de interés, no forman parte de la acción. Lo único relevante es la exterioridad en la que consiste el acto humano concreto ${ }^{3}$. Si el ser humano no es necesariamente

2 Me he ocupado extensamente de esta cuestión en RIVAs, P., Fusticia, Comunidad, Obediencia. El pensamiento de Sócrates ante la ley, Eunsa, Pamplona, 1996, passim. Resultan de especial utilidad los trabajos ya clásicos de Adkins, A. W. H., Merit and Responsability. A Study in Greek Values, Clarendon Press, Oxford, 1960; Cornford, F. M., From Religion to Philosophy, Cambridge University Press, Cambridge, 1912. (Hay traducción española de Antonio Pérez Ramos, Barcelona, Ariel, 1984); DodDs, E. R., The Greeks and the irrational, University of California, 1955. (Hay traducción española de María Araujo, Alianza, Madrid, 1986); JAEger, W., Paideia die Formung des griechischen Menschen, De Gruyter, Berlin, 1939-1944. (Hay traducción española en México, Fondo de Cultura Económica, 1982); Lloyd-JonEs, H., The fustice of Zeus, University of California Press, Berkeley, 1971; Nestle, W., Vom Mythos zum Logos, Scientia Verlag, Aalen, 1966.

3 En perfecta coherencia con este objetivismo extremo aparece el importante papel que la fama, el honor y la vergüenza poseían para el hombre del momento histórico que tratamos. Si tanto el que obra como el que juzga las acciones ajenas no conceden alcance alguno a lo que ocurre en la interioridad del agente, entonces la relevancia reside en el juicio de los demás. El sujeto de la acción no tiene más datos para juzgar moralmente su propia acción que los que tienen aquellos que le contemplan, es decir los elementos externos, los que se manifiestan. Por eso el verdade- 
el origen y principio de sus propios actos, no puede hablarse de un verdadero sujeto y motor de la acción y, en último término, puede resultar engañoso calificar de «humanas» tales acciones. Como consecuencia, no tiene cabida un juicio subjetivo sobre las propias acciones, ni hay una autoconciencia más allá de lo que los demás consideran que uno es. La interioridad del ser humano se nos presenta como radicalmente pobre y carente de valor. Un calificativo referido a un sujeto humano no expresará un hábito sino más bien la evidencia de que dicho sujeto ha ejecutado una serie de actos que manifiestan tal calificativo.

La actitud socrática ante la realidad humana es bien distinta y esto lo convierte en una segunda referencia ineludible sobre la cuestión. Su insistencia en distinguir lo verdadero de lo falso, la acción correcta de la incorrecta ${ }^{4}$; la misión recibida de llevar a los atenienses por el camino de la verdad y del bien ${ }^{5}$; el empleo de un método racional para lograr tales objetivos ${ }^{6}$; su afirmación de que lo que realmente importa es llevar a cabo una vida buena ${ }^{7}$ y que, por consiguiente, las propias acciones importan en cuanto nos hacen mejores o peores $^{8}$; su insistencia en que de ningún modo se debe obrar injustamente ${ }^{9}$, al punto de que es mejor sufrir injusticia que cometerla ${ }^{10}$; el principio «conócete a ti mismo», etc.; todo ello nos presenta una profunda visión del ser humano, que encuentra en el hombre la sede real de la moralidad, el principio originario y profundo de sus acciones. Se toma conciencia de quién se es, se produce un distanciamiento definitivo respecto de los objetos de conocimiento ${ }^{11}$. Evidentemente, Sócrates no formula una teoría del conocimiento ni distingue facultades, actos, etc. Pero sí reconoce una verdadera conciencia de sí mismo en el hombre, lo considera un yo. Se manifiesta ese autogobierno, esa absoluta

ro mal es la vergüenza, el oprobio consecuente a haber cometido acciones indignas aunque se hayan hecho de forma inadvertida. Y simultáneamente el bien más alto es la fama y el honor, el buen juicio que los demás poseen de uno mismo. La expresión «cultura de la vergüenza» para referirse a esta mentalidad aparece en DODDS, E. R., cit., pp. 28-50 y en LlOYD-JONES, H., cit., pp. 24-6.

4 Critón, 49 a2-c1.

5 Apología, 28 d7-29 a1, Apología, 29 c8-d5, Critón, 48 b5-8.

6 Critón, 46 b3-10.

7 Critón, 48 b5-8.

8 Critón, 47 c8-48 a1.

9 Critón, 49 b9-10, Apología, 29, b7-8, Apología, 32 d3.

10 Gorgias, $469 \mathrm{c1-2.}$

11 Cfr. el estudio clásico de Havelock, E. A., Preface to Plato, Basil Blackwell, Oxford, 1963, pp. 197-9. 
autocracia del verdadero yo ${ }^{12}$. Ahora existe una unidad en el hombre que da sentido y coherencia a sus acciones.

A mi juicio, la relevancia de esta cuestión reside en que para Sócrates la virtud no es ya ni mera destreza que se posee en un grado eminentemente superior, ni simple reconocimiento. Los actos son realmente propios, sin que haya que salir fuera para buscar su sentido ni su origen. $\mathrm{Y}$ a la vez las acciones constituyen nuestro modo de ser, nos hacen. Es decir, uno se configura a sí mismo y, sobre todo, ante sí mismo.

Pero Sócrates excede su propio pensamiento, viniendo a ser más relevante si cabe su propia personalidad, al extremo de que Platón no duda en calificarlo como «el mejor hombre», «el más inteligente y más justo» ${ }^{13}$. De esta forma nos encontramos ante la figura que no sólo inaugura el pensamiento ético característico de la cultura occidental sino que resulta ser también el paradigma de hombre para la filosofía posterior a él.

Ahora bien, ante la acusación que le condujo a la condena a muerte, Sócrates no guarda rencor contra sus acusadores ni contra quienes le condenan ${ }^{14}$ o al menos no mucho ${ }^{15}$. Con todo, el motivo es la convicción socrática de que no puede recibir daño alguno de los acusadores, porque no cree «que naturalmente esté permitido que un hombre bueno reciba daño de otro malo» ${ }^{16}$ Lo cual no ahorra que exprese con claridad su juicio sobre ellos: que son «condenados por la verdad, culpables de perversidad e injusticia $\gg^{17} \mathrm{y}$, porque creen poder hacerle daño, «es justo que se les haga este reproche» ${ }^{18}$ La situación de Sócrates no es la de quien perdona un daño, sino solamente la de quien afirma que no puede ser dañado. Aunque se separa, como es coherente con lo dicho en párrafos anteriores, la intención de dañar y el daño, e incluso se condena esa intención que no logra su propósito; no estamos realmente ante el perdón tal y como lo comprendemos habitualmente hoy. Porque, en realidad, Sócrates, que es el paradigma de quien vive una vida buena y lograda, no necesita del

12 Cfr. Cornford, F. M., Antes y después de Sócrates, Ariel, Barcelona, 1980, p. 45. Es traducción de la edición inglesa Before and after Socrates, Cambridge University Press, Londres, Cambridge, 1926.

13 Fedón, 118 a.

14 Apología, 35 e1-36 a1.

15 Apología, 41 d5-6.

16 Apología, 30 c7-d1.

17 Apología, 39 b4-5.

18 Apología, $41 \mathrm{~d} 7-\mathrm{e} 1$. 
perdón. Su actitud ante las ofensas es precisamente la propia de quien, tiempo después, Aristóteles va a caracterizar como el paradigma del hombre bueno y virtuoso.

Con todo, si tratamos de buscar una doctrina aristotélica sobre el perdón, lo que encontramos refuerza lo ya apuntado, pues el resultado es casi una total ausencia de referencias y un «perdón» distinto al que nos es común.

En efecto, en la Ética a Nicómaco, Aristóteles menciona la necesidad de la «indulgencia ( $\sigma v \gamma \gamma v \omega ́ \mu \eta)$ cuando uno hace lo que no debe sometido a una presión que rebasa la naturaleza humana y que nadie podría soportar» ${ }^{19}$, y de

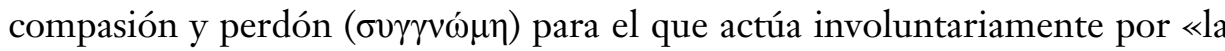
ignorancia concreta de las circunstancias y el objeto de la acción» ${ }^{20}$. Con el mismo sentido y a propósito de la incontinencia $(\alpha \kappa \rho \alpha \sigma i \alpha)$, Aristóteles sostie-

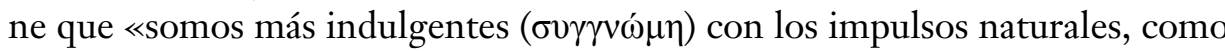
también con las pasiones que son comunes a todos» ${ }^{21}$. Y de modo similar afirma que «no es de extrañar si uno es vencido por placeres o dolores fuertes

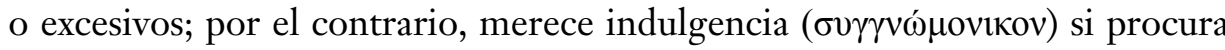
resistir $\gg^{22}$. Se trata, en suma, de comprender, excusar o disculpar acciones a causa de las circunstancias, pero en este contexto no se hace siquiera referencia a quien sufre o padece dichas acciones.

Esta percepción de lo que significa el perdón para Aristóteles se completa mejor con algunas referencias al magnánimo ( $\mu \varepsilon \gamma \alpha \lambda$ ó $v \vee \chi o \varsigma)$. El que «tiene grandes pretensiones y es digno de ellas $»^{23}$, el que posee «la grandeza en todas las virtudes» ${ }^{24}$. El magnánimo «desprecia el deshonor $(\alpha \tau \mu \iota \alpha)$ porque no será justo tratándose de él» $\gg^{25}$. Aún más: siempre desprecia con justicia porque su opinión es verdadera. Hace beneficios pero se avergüenza de recibirlos; recuerda el bien que hace pero no el que recibe; no necesita nada ${ }^{26}$. Pero sobre todo, no es rencoroso ( $\mu \downarrow \eta \sigma i \kappa \alpha \kappa o \varsigma)$, «pues no es propio del magnánimo guardar las cosas en la memoria, especialmente malas, sino más bien pasarlas por

19 ARISTÓTELES, Ética a Nicómaco, III 1, 1110 a 23-25. Se cita por la edición bilingüe y traducción de María Araujo y Julián Marías ( $7^{\mathrm{a}}$ ed.), Centro de Estudios Políticos y Constitucionales, Madrid, 1999.

20 Ibid., III, 1,1111 a $1-2$.

21 Ibid., VII, 6, 1149 b 3-6.

22 Ibid., VII, 7, 1150 b 6-8.

23 Ibid., IV, 3, 1123 b 2.

24 Ibid., IV, 3, 1123 b 30-31.

25 Ibid., IV, 3, 1124 a 11-12.

26 Cfr. ibid., IV, 3, 1124 b 6-19. 
alto» ${ }^{27}$. En definitiva, el paradigma de quien posee la virtud en mayor grado no tiene relación alguna con lo que entendemos por perdonar, pues ni necesita nunca pedir perdón ni tampoco necesita concederlo.

El último referente de la Antigüedad clásica es Séneca, no sólo por el interés moral de la doctrina estoica en la que cabe encuadrarlo, sino por haber escrito una obra titulada precisamente De Clementia. Séneca define la clemencia como «la moderación interior (temperantia animi) aplicada a la capacidad de aplicar un castigo, o la comprensión (lenitas) de un superior frente a un inferior al decidir una pena. (...) De modo que puede decirse que hay que procurar inclinarse (inclinatio animi) a la suavidad en la pena $\gg^{28}$. Como se ve, se trata de una actitud no general sino de quien tiene la función que castigar, y referida principalmente a ofensas que han recibido otros. Todo ello aleja la clemencia del perdón. Además, cuando Séneca indica los vicios opuestos a la clemencia volvemos a encontrarnos lejos del sentido del perdón. En efecto, por un lado se opone a la clemencia «la crueldad (crudelitas) que no es otra cosa que la brutalidad en la aplicación de las penas. (...) Crueldad es la tendencia (inclinatio animi) a las medidas más duras» ${ }^{29}$. Y, por el otro, la compasión (misericordia), en la que incurrimos «bajo la apariencia de clemencia» ${ }^{30}$. Más allá de que tanto la expresión latina (misericordia) como el término empleado para traducirla (compasión) tengan un sentido positivo en nuestro lenguaje presente, ni la crueldad ni la compasión entran en el léxico próximo al perdón.

Aún más, la descripción del compasivo pareciera situar al clemente próximo al $\mu \varepsilon \gamma \alpha \lambda{ }^{\prime} \psi v \chi 0 \varsigma$ aristotélico. En efecto, para Séneca, «todos los hombres de bien se mostrarán clementes y comprensivos (clementiam mansuetudinemque praestabunt) y evitarán la compasión (misericordia). En efecto, es un fallo del espíritu apocado (vitium pusilli animi) que se derrumba al contemplar las desdichas de los demás» ${ }^{31}$. Con mayor claridad se observa cuando poco más adelante insiste en que «la compasión es una enfermedad del espíritu (aegritudo animi) que se contrae al contemplar las desgracias de los demás, o una depresión (tristitia) causada por los males de los demás, que cree que suceden a

27 Ibid., IV, 3, 1125 a 3-5.

28 LuCIO ANNEO SÉNECA, De Clementia II 3, 1. Se cita por la edición bilingüe con estudio preliminar, traducción y notas de Carmen Codoñer, Tecnos, Madrid, 1988.

29 Ibid., II 4, 1.

30 Ibid., II 5, 1.

31 Ibidem. 
quienes no lo merecen. Y la enfermedad no recae sobre el sabio: su mente está serena y no puede sucederle nada que la ofusque. Nada le es tan adecuado a un hombre como la grandeza de ánimo (magnus animus), y no puede la grandeza coexistir con la tristeza $\gg^{32}$.

Y finalmente considera Séneca la venia, que podría traducirse con reservas por perdón. Según él, el sabio no debe otorgarlo porque es «la absolución del castigo merecido» ${ }^{33}$. Sin embargo, «aquello que quieres conseguir con el perdón te lo otorgará por un camino más digno. En efecto, el sabio será indulgente, dará su opinión y corregirá (parcet, consulet et corriget); hará lo mismo que si perdonara, y no perdonará, ya que el que perdona reconoce que ha omitido algo que hubiera debido hacerse. (...) Todo esto no es obra del perdón, sino de la clemencia» ${ }^{34}$. Que el texto complica más que facilita las cosas, se observa por el hecho de que Séneca afirma que es propio del sabio el parcere, que comúnmente traducimos por «perdonar». Pero, más allá de los sentidos de los términos está el problema de explicar cómo es posible hacer lo mismo que si perdonara y no perdonar, ser indulgente (parcere) y no otorgar el perdón (venia).

Por último, se aleja de nuevo de nuestro sentido habitual del perdón cuando incluye la clemencia como parte de la justicia. Porque, en efecto, «no hace nada de esto como si no alcanzara a la justicia, sino como si lo que ha decidido fuese lo más justo ${ }^{35}$. De nuevo, se ve, como en los párrafos anteriores, que cuando habla de perdonar se refiere a no sancionar. De todas formas también parece que la clemencia puede llevar a veces a no sancionar. Lo que distingue a una de otra es la justicia: el clemente obra de modo justo (aquí la moderación o equidad se ven como partes de la justicia), el que perdona o se compadece, no.

$32 \mathrm{Ibid}$., II 5, 4. Hay quien ha indicado que existen otros textos de Séneca que indican que la clemencia no sería entendida como una forma de arrogancia (cfr. D. KONSTAN, «Clemency as a virtue», Classical Pbilology 100 (2005), pp. 337-339). Con todo, no es sin más una reproducción del modelo aristotélico, pues poco después, en II 6, 1, Séneca precisa que «el sabio no se compadecerá, sino que acudirá en ayuda, prestará su apoyo, nacido para servir a la comunidad y para el bien de la comunidad, del cual otorgará a cada cual su parte. También transmitirá su bondad a las víctimas de las desgracias en la medida en que lo merezcan, a los que merecen reproches y necesitan enmienda; acudirá con mucho más interés en favor de los afligidos y de los que sin razón se ven agobiados por la angustia».

33 Ibid., II 7, 1.

34 Ibid., II 7, 1-3.

35 Ibid., II 7, 3. 
La impresión general, por lo que llevamos visto, es que no encontramos en Séneca la claridad y la precisión que desearíamos ${ }^{36}$. Por eso, a veces parece reproducir de nuevo el magnánimo de Aristóteles, que está por encima de las ofensas. $Y$ en otros casos parece ir más allá describiendo una disposición interior más rica y compleja e incluso más cercana a una perspectiva cristiana del perdón o al menos de la compasión y misericordia (aunque rechace los términos misericordia y venia, y emplee en cambio clementia). Más allá de esta falta de claridad hay que insistir de nuevo en que no estamos ante la situación de quien ha recibido un agravio u ofensa sino ante la de quien tiene la función o el cargo público que incluye la potestad de sancionar. De esta forma no parece añadir apenas a nuestra búsqueda de un sentido filosófico del perdón antecedente al cristianismo.

\section{VERSIONES CONTEMPORÁNEAS DEL PERDÓN}

Pero para lograr resolver la pregunta inicial acerca de la posibilidad de un sentido puramente filosófico del perdón no basta con observar el tiempo anterior a la aparición del cristianismo en la cultura y mentalidad occidental. Es necesario comprobar también si se han dado en el pensamiento más contemporáneo intentos de formular una aproximación filosófica al perdón al margen de su anclaje religioso. Tal vez por esta dificultad de encontrar un apoyo en los sentidos del perdón en la tradición filosófica clásica, quienes han tratado de hacer estudios integrales sobre el perdón pero manteniéndose en el terreno de la especulación puramente filosófica, han optado por una reflexión descriptiva sobre nuestras precomprensiones comunes o nuestras intuiciones más básicas sobre el mismo. Para ello cabe, por ejemplo, una aproximación fenomenológica que pase revista a todo aquello que no es el perdón con vistas a deslindar después el objeto específico del mismo, las condiciones de su otorgamiento y sus rasgos o características propias ${ }^{37}$. Por otro lado, también es posible un

36 Aunque queda lejos de nuestro propósito, hay que señalar también que es un lugar común mostrar las diferencias e incluso contradicciones entre el libro I y el II del De clementia (al respecto, KöNZÖL, M., «Clemency and justice in the De Clementia of Seneca», Iustum Aequum Salutare IV (2008), p. 67). Además, hay quien ha indicado otras diferencias importantes con respecto a otros escritos del mismo Séneca (cfr. FlamerIE DE LACHAPELLE, G., «Trois traits négatifs de la misericordia dans le second livre du De Clementia de Sénèque», Les Études Classiques 74 (2006), pp. 312-314).

37 Cfr. Crespo, M., El perdón. Una investigación filosófica, Ediciones Encuentro, Madrid, 2004. 
acercamiento más dialéctico que sin embargo busque responder a prácticamente las mismas cuestiones (concepto; relaciones con fenómenos como rencor, odio, piedad o retribución; aspectos jurídicos, morales, religiosos). Este es el caso del libro conjunto de Murphy y Hampton, que se ha convertido en referencia habitual del debate en el ámbito anglosajón durante los últimos veinte años ${ }^{38}$. Incluso hay quien recientemente ha tratado de combinar el estudio histórico con el análisis filosófico y la perspectiva política más actual ${ }^{39}$.

Sin embargo, si buscamos entre los pensadores mayores de los últimos años, la generalidad de quienes se han ocupado de la cuestión han sido filósofos inclasificables. Y, a diferencia del grupo anterior, en absoluto metódicos.

Por citar a un clásico del pasado siglo, Hannah Arendt ha dedicado unas breves páginas de su obra The Human Condition para mostrar la importancia del perdón para la realidad política, habida cuenta de su condición de remedio de la irreversibilidad del proceso iniciado por el actuar. El lugar del perdón no es incidental para el pensamiento político de Arendt. Es más, parece ser un elemento clave en la construcción de su propio pensamiento. En efecto, recuerda en primer lugar que el ser humano como animal laborans se redime de su encarcelamiento en el ciclo de labor y consumo a través del hacer-fabricarproducir que lo libera del dolor del laborar. Esas capacidades de hacer, fabricar y producir son propias del ser humano como bomo faber ${ }^{40}$. Por otro lado, el bomo faber se redime de su insignificancia, de la devaluación de todo valor y la imposibilidad de hallar modelos válidos en sí, a través de las facultades interrelacionadas de la acción y el discurso que producen historias con significado. En ambos casos, lo que redime al ser humano viene del exterior de la acción, es decir de fuera de las acciones propias del animal laborans (labor y consumo) y del bomo faber (fabricación). En efecto, son las actividades del homo faber las que nos redimen del animal laborans, y son las actividades de la acción y el discurso las que nos redimen del bomo faber. Ahora bien, también la acción y el discurso tienen unos límites que debes ser redimidos: la irreversibilidad y el carácter no conjeturable del proceso iniciado por el actuar (o sea, la imposibilidad de predecir el futuro). En este caso, no tenemos ya una facultad superior sino que

38 Cfr. Murphy, J. G. y Hampton, J., Forgiveness and Mercy, Cambridge University Press, Cambridge, 1988.

39 Cfr. GRISwOld, Ch. L., cit.

40 Cfr. Arendt, H., The Human Condition, The University of Chicago Press, Chicago, 1958. Se emplea la traducción castellana de Ramón Gil Novales, La condición bumana, Paidós, Barcelona, 1993 , p. 255. 
el remedio está en las potencialidades de la acción: la facultad de perdonar y la facultad de prometer nos redimen respectivamente de la irreversibilidad y lo impredecible. Perdonar «sirve para deshacer los actos del pasado» ${ }^{41}$. Sin ser perdonados nuestra capacidad para actuar quedaría «confinada a un solo acto del que nunca podríamos recobrarnos» ${ }^{42}$. La facultad de perdonar depende de la pluralidad, presencia y actuación de otros, porque nadie puede perdonarse a sí mismo ${ }^{43}$.

Arendt sostiene que «el descubridor del papel del perdón en los asuntos humanos es Jesús de Nazareth $»^{44}$, al margen de incidentales signos rudimentarios como el principio romano de ahorrar la vida del vencido. De ahí que se detenga en una breve exégesis de algunos textos evangélicos para entenderlos en un sentido estrictamente secular ${ }^{45}$. Según su interpretación, Jesús mantuvo que no sólo Dios tiene el poder de perdonar sino también los hombres, que deben poner en movimiento el perdón para ser perdonados por Dios. El deber de perdonar nace de que «no saben lo que hacen» y por eso no se aplica al mal deseado con conocimiento, que por otro lado es infrecuente. Para que la vida prosiga es necesario exonerar constantemente a los hombres de lo que han hecho sin saberlo ${ }^{46}$.

El perdón es el extremo opuesto a la venganza. Esta última hace permanecer en el individuo el proceso de reacción natural y automático. En cambio, el perdón es impredecible e inesperado. Por eso mismo no es reactivo sino original, es decir es una nueva acción no condicionada por el acto que la provocó y libre de sus consecuencias ${ }^{47}$.

El perdón y la relación que establece siempre es un asunto eminentemente personal en el que lo hecho se perdona por amor a quien lo hizo ${ }^{48}$. De ahí la convicción corriente de que sólo el amor tiene poder para perdonar. Precisamente por su capacidad para descubrir el quién, por su desinterés, el amor no es mundano y por tanto es antipolítico ${ }^{49}$. Pareciera entonces que el perdón

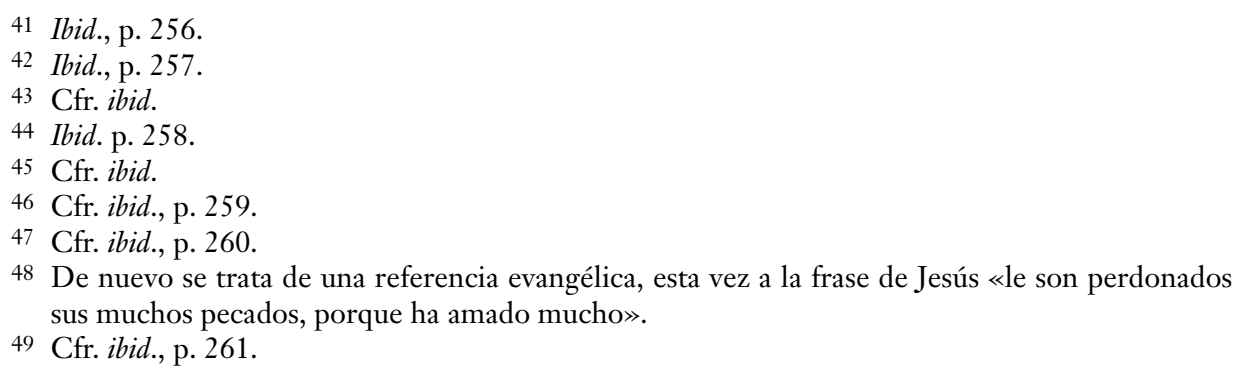


queda al margen de la realidad política. Sin embargo, cabe un tipo de amistad «sin intimidad ni proximidad», similar a la amistad política ( $\varphi \imath \lambda i \alpha \pi 0 \lambda \iota \tau \iota \kappa \eta ́)$ aristotélica: el respeto, como consideración hacia la persona independientemente de sus cualidades o logros. El respeto es «totalmente suficiente para impulsar el perdón de lo que hizo una persona, por amor a la persona $\gg^{50}$. Y así terminan las consideraciones de Arendt, sin explicar más en detalle en qué consiste ese respeto y por qué es suficiente para generar perdón manteniéndolo en los límites de lo político.

Estas breves páginas de Arendt han suscitado breves menciones en el contexto de los estudios comprehensivos de su filosofía política y aun de su pensamiento en general. En pocos casos, se ha intentado resolver las dudas que plantea, señalar los motivos que subyacen, determinar su alcance o discutir su contenido. De entre estos últimos, cabe traer a colación a los que arrojan algo de luz sobre la posición arendtiana.

Un problema manifiesto de comprensión de las tesis de Arendt radica en el alcance de la afirmación de que se perdona la acción cometida no a sabiendas. Y es que aparentemente una acción así sería precisamente la que cae fuera del ámbito del perdón porque se trata de una acción excusable. Al mismo tiempo Arendt distingue entre el mal cometido a sabiendas del que no. Según Pettigrove, para Arendt la mayoría de las malas acciones no tienen un propósito perverso, sino que son movidas por la conveniencia, el interés, el afán de medrar, la cobardía, el ansia de poder, la codicia y similares. De ahí que estemos habitualmente ante meras faltas o transgresiones pero no ante verdaderos crímenes y males buscados por afán de dañar al que lo sufre. Por eso es posible el perdón, porque tales motivos que impulsan esas acciones nos son familiares en la medida en que hemos obrado bajo su impulso. De ahí que Arendt invoque nuestra experiencia de que quien comete tales faltas puede cambiar y empezar de nuevo. En cambio, en las acciones en las que el daño es buscado por sí mismo no cabría el perdón ni restablecer la relación rota con el ofensor ${ }^{51}$.

Con respecto al motivo que puede llevar a Arendt a defender ese lugar del perdón en la comunidad política, Janover resalta la conexión del perdón y la promesa con la condición humana de la pluralidad. Y es que para Arendt la pluralidad describe el hecho de que los seres humanos son al mismo tiempo miembros

50 Cfr. ibid., p. 262.

51 Cfr. Pettigrove, G., «Hannah Arendt and Collective Forgiving», Fournal of Social Philosophy 37 (4) (2006), pp. 486-487. 
de la misma especie y diferentes uno de otro. Esta revelación de la identidad vendría a ser para Arendt el rasgo ontológico clave de la existencia humana ${ }^{52}$.

Smith, por su parte, ha ido a buscar los motivos arendtianos en aspectos más profundos y radicales aunque parezcan meramente psicológicos. En efecto, Smith sostiene que es la desesperación frente a la no redención de la acción política lo que lleva a Arendt a introducir el perdón en el ámbito de lo políti$\mathrm{co}^{53}$. En realidad, se entiende mejor esta inclusión en el contexto del empeño de Arendt por huir del materialismo y la despersonalización de la vida pública, así como de la pérdida del respeto por la persona, que son todas ellas características endémicas de la sociedad moderna. Aún más, su apelación al perdón sería un ataque contra el carácter destructivo de la violencia y en especial de la violencia del totalitarismo. En pocas palabras, se trata de un intento de redimir a la sociedad de la violencia ${ }^{54}$.

Por último, en relación al propio contenido, hay que empezar indicando a quien como Pettigrove resalta la ventaja del planteamiento de Arendt porque ésta se distancia de la discusión contemporánea del perdón. En efecto, tal discusión tiende a centrarse en las emociones que se experimentan al perdonar en lugar de en las actividades que se llevan a cabo al perdonar. Así, al detenerse en los aspectos emocionales se pone la atención en algo que difícilmente puede ser compartido de la misma forma y, por tanto, que no puede ser realmente común. Y, en consecuencia, no puede tener relevancia alguna para la vida política de una comunidad. En cambio, Arendt considera sobre todo los elementos de la acción de perdonar. Pettigrove señala la importancia de que se conecte con la promesa, en la medida en que esta última se percibe siempre al margen de los sentimientos que puedan estar asociados a ella ${ }^{55}$. De ahí que cuando se hable de que una comunidad puede ofrecer su perdón a otra comunidad que le causó daño, no se trate de la expresión de ningún sentimiento o emoción colectiva de la comunidad agredida. Más bien se trata del compromiso de establecer una relación al margen del daño causado. Tal relación se concretará en determinadas políticas públicas que demuestren esa voluntad de que las ofensas pasadas no establezcan las condiciones de las relaciones futuras ${ }^{56}$.

52 Cfr. Janover, M., «The Limits of Forgiveness and the Ends of Politics», Fournal of Intercultural Studies 26 (3) (2005), p. 229.

53 Cfr. SMith, R. W., «Redemption and Politics», Political Science Quarterly 86 (2) (1971), p. 218.

54 Cfr. ibid., p. 223.

55 Cfr. PetTigrove, G., cit., pp. 485-486.

56 Cfr. ibid., p. 492. 
En cambio, cabe señalar las limitaciones del respeto como amistad política. Janover sostiene que puede tratarse de un posible fundamento para el perdón en situaciones políticas de conflicto donde amenacen reacciones de venganza sin término. Pero hay ocasiones en los que es ese mismo respeto el que ha sido destruido por la violencia y el odio dentro de una misma comunidad. En tales circunstancias la concepción de Arendt del perdón político no puede servirnos ${ }^{57}$.

Y más allá, es posible criticar no sólo los límites sino el carácter ilusorio de las tesis de Arendt. A juicio de Smith, éstas son irreales y tienen consecuencias inaceptables. Por un lado, porque si se perdona en consideración a quién cometió la ofensa y no a la ofensa en sí, es necesario compartir con el ofensor la misma condición de debilidad. El problema es que el hombre moderno es un extraño para todos menos para su círculo íntimo. En realidad somos funciones y roles los unos para los otros. $\mathrm{Y}$ así el perdón político no es una posibilidad genuina en la sociedad moderna ${ }^{58}$. Por todo ello, lo que convierte en irreal el intento de Arendt es que exige alienarse de la sociedad realmente existente. El perdón se ha convertido así en una abstracción, en un concepto y no en una experiencia ${ }^{59}$.

A mi juicio, no es necesario compartir la visión del hombre moderno que trasluce Smith en su crítica a Arendt, para coincidir en las dificultades operativas del planteamiento de esta última. La ausencia de una explicación

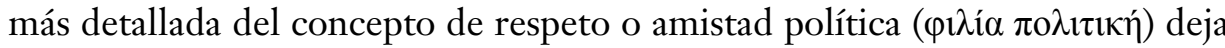
truncada la visión de Arendt acerca del perdón en la vida política ${ }^{60}$. De esta forma, aun resultando una tesis provocativa, requiere para ser pensada de la inversión de buena parte de la teoría política contemporánea, algo que nadie parece estar en condiciones de hacer. Y así, pretendiendo hacer un espacio al perdón, parece quedar claro que tal espacio no existe.

El otro pensador paradigmático contemporáneo que ha tratado de formular una comprensión secular del perdón ha sido Jacques Derrida. En él la falta de método se hace más patente, con su proverbial querencia por el ensayo literario. Hay que advertir con todo que Derrida parte de alguna forma de las tesis de otro filósofo francés casi contemporáneo suyo, Vladimir

57 Cfr. Janover, M., cit., p. 230.

58 Cfr. SмIтH, R. W., cit., pp. 219-220.

59 Cfr. ibid., p. 224.

60 Un desarrollo así sería tarea de un discípulo y Arendt parece haber tenido multitud de comentadores pero no discípulos. 
Jankelevitch. Este último expone con fuerza la paradoja del carácter gratuito y completo del perdón puro, el único y verdadero perdón ${ }^{61}$. En una obra posterior, lleva al extremo la perplejidad del lector al defender la legitimidad o licitud de la negativa absoluta a perdonar. El propio Jankelevitch acepta la contradicción y el carácter irresoluble de la misma ${ }^{62}$. Por su parte, Derrida afronta el problema en un seminario cuyo contenido se conoce hasta el momento por medio de una entrevista, lo que aumenta carácter fragmentario de lo que sostiene.

En su aproximación al perdón ${ }^{63}$, Derrida parte de las preguntas básicas referidas, por un lado, a su diferenciación con temas aledaños, y por otro a los intentos de universalizar un fenómeno cuyo escenario, figura y lenguaje pertenecen a una herencia religiosa determinada (la abrahámica) ${ }^{64}$. El momento actual nos presenta «una humanidad sacudida por un movimiento que pretende ser unánime», más aún ante la manifestación de «un género humano que pretendería acusarse repentinamente, y públicamente, y espectacularmente, de todos los crímenes efectivamente cometidos por él mismo contra él mismo, 'contra la humanidad' $\gg^{65}$. Una realidad así le mueve a temer que detrás se esconda el simulacro, la hipocresía o el cálculo.

Frente a este panorama, lanza una proposición arriesgada: «cada vez que el perdón está al servicio de una finalidad, aunque ésta sea noble y espiritual (liberación o redención, reconciliación, salvación), cada vez que tiende a restablecer una normalidad (social, nacional, política, psicológica) mediante un trabajo de duelo, mediante alguna terapia o ecología de la memoria, entonces el 'perdón' no es puro ni lo es su concepto». Por eso, «el perdón no es, no debería ser, ni normal, ni normativo, ni normalizante. Debería permanecer excepcional y extraordinario, sometido a la prueba de lo imposible: como si interrumpiese el curso ordinario de la temporalidad histórica» ${ }^{66}$.

61 Cfr. JankéLÉvitch, V., Le pardon, Paris, Editions Montaigne, 1967, especialmente el capítulo III. Hay traducción castellana de Núñez del Rincón, Seix Barral, Madrid, 1999.

62 Cfr. Jankélévitch, V., «Pardonner?» (1971), en L'imprescriptible, Seuil, Paris, 1986.

63 A pesar de que se trata de una entrevista y en ese sentido no pareciera un escrito académico, hay que tener en cuenta, como señala el propio Derrida, que el perdón fue el objeto del seminario que imparte en la École des Hautes Études en Sciences Sociales durante los tres años anteriores. De ahí que sus respuestas no sean al paso, como en una entrevista común.

64 Cfr. Derrida, J., El siglo y el perdón seguido de Fe y saber, Ediciones de la Flor, Buenos Aires, 2003, pp. 7-8.

65 Ibid., p. 9.

66 Ibid., p. 12. 
Llevando lo anterior al terreno de lo paradójico, señala que lo único a perdonar es lo imperdonable: «no se puede o no se debería perdonar, no hay perdón, si lo hay, más que ahí donde existe lo imperdonable. Vale decir que el perdón debe presentarse como lo imposible mismo. Sólo puede ser posible si es imposible» ${ }^{67}$. Más allá de los recursos literarios y del esfuerzo por ganar en expresividad aun a costa de la hipérbole, es necesario detenerse en su explicación. Y es que la invocación a la condición de petición de perdón por parte del ofensor para que se dé el perdón le parece recusable, toda vez que introduce una lógica condicional del intercambio. Estaríamos ante una transacción económica que confirma y contradice a la vez esa tradición abrahámica. A la vez, porque dicha tradición comparte la exigencia del perdón incondicional, gratuito, infinito, sin contrapartida para el culpable; junto con el perdón condicional proporcional al arrepentimiento y la transformación de quien de esta forma ya no es el culpable ${ }^{68}$.

Derrida incide en que esa idea de la incondicionalidad del verdadero perdón que lo convierte en algo aparentemente excesivo, hiperbólico, loco ${ }^{69}$. Por eso, «el perdón puro e incondicional, para tener su sentido estricto, debe no tener ningún 'sentido', incluso ninguna finalidad, ninguna inteligibilidad $\gg^{70}$. $\mathrm{Y}$, en una afirmación que hace intuir una lectura de Arendt, sostiene que el perdón tal vez sea «lo único que ocurra, que sorprenda, como una revolución, el curso ordinario de la historia, de la política y del derecho. Porque esto quiere decir que sigue siendo heterogéneo al orden de lo político o de lo jurídico» ${ }^{71}$. Ambos polos del perdón (el incondicional y el condicional) son «absolutamente heterogéneos y deben permanecer irreductibles uno al otro». Pero, al mismo tiempo son indisociables porque para que el perdón se haga efectivo hace falta que «su pureza se comprometa en una serie de condiciones de todo tipo (psico-sociológicas, políticas, etc.)» $\gg^{72}$.

Sin embargo, cuando las preguntas plantean los problemas del perdón ante situaciones recientes de graves violaciones de los derechos humanos, Derrida responde siempre en términos genéricos y eludiendo sacar las consecuencias de sus tesis recién expuestas ${ }^{73}$. De ahí que la mayoría de los comenta-

67 Ibid., pp. 12-13.

68 Cfr. ibid., pp. 14-15.

69 Cfr. ibid., p. 19.

70 Ibid., p. 24.

71 Ibid., p. 19.

72 Ibid., p. 24.

73 Cfr. ibid., pp. 28-35. 
rios al planteamiento de Derrida parecen seguir un mismo esquema: tratar de comprenderlo pero sin ocultar sus límites.

Se puede señalar así que Derrida está diciendo cosas importantes sobre el perdón de modo paradójico, al mismo tiempo que incurre en aporías evidentes si se confronta con nuestras ideas comunes sobre el mismo. Y lo grave es que dichas aporías tienen que ver con las consecuencias morales de sus tesis. Aunque Derrida no las extrae, éstas son inevitables ${ }^{74}$. Con la aporía del perdón estaría intensificando la experiencia de la decisión y la responsabilidad que se hacen presentes en la decisión y la responsabilidad de perdonar. Porque, en definitiva, sólo así se evitan la corrupción y la trivialización del perdón ${ }^{75}$. Con todo, habría que señalar también los límites de su tendencia a la exageración, por ejemplo con respecto al carácter ininteligible del perdón, porque tal rasgo supone convertir en iguales situaciones de ofensa y perdón muy diferentes entre sí. De igual modo, la visión economicista del perdón condicional es contraintuitiva y oscurece muchas de las experiencias humanas comunes, que muestran que cabe un perdón condicional alejado de cálculos e intercambios ${ }^{76}$.

Aunque se apunte el acierto del planteamiento hiperbólico de Derrida, porque señala al carácter excéntrico e infinito de la decisión ética; empero, debe señalarse que el concepto de perdón puro, extraordinario e incondicional que sostiene Derrida es semejante al de gracia divina ${ }^{77}$, como un tipo de absolución, que es divina, sobrenatural, más que humana en todo caso $^{78}$. Además tomar en serio el planteamiento de Derrida supondría aceptar como caso central el mal radical, por ejemplo el holocausto. Y, sin embargo, Derrida evita cuidadosamente sacar una consecuencia de ese género ${ }^{79}$.

En realidad, una somera lectura de la entrevista muestra al lector que Derrida parece no tomarse en serio a sí mismo. Fundamentalmente porque

74 Cfr. Thompson, J., «Is Apology a Sorry Affair? Derrida and the Moral Force of the Impossible», The Philosophical Forum 41 (2010), pp. 271-272.

75 Cfr. Bernstein, R. J., «Derrida: The Aporia of Forgiveness», Constellations 13 (2006), p. 398 399.

76 Cfr. ibid., 400-401.

77 Cfr. JanOver, M., cit., pp. 225-226.

78 Cfr. ibid., p. 231.

79 Cfr. ibid., pp. 227-228. Con todo, no es el único concepto problemático en Derrida por sus consecuencias morales, pues algo similar ocurre con la memoria (al respecto, cfr. VERDEJA, E., «Derrida and the Impossibility of Forgiveness», Contemporary Political Theory 3 (2004), p. 33). 
evita, con intención o sin ella, las consecuencias de su posición. Su tesis llama la atención sobre un elemento importante del perdón, pero para eso no hace falta oscurecer el resto del panorama. Dicho de otra forma, las paradojas son interesantes y provocan nuestro pensamiento, siempre que sean verdad. O si se prefiere, siempre que no oculten más verdad de la que desvelan. Sobre todo cuando las verdades que se ocultan tiene que ver con las experiencias comunes y ordinarias de todos los seres humanos. Porque entonces la impresión que deja al lector es que el creador de paradojas vive en un mundo extraño, ajeno, alejado de las realidades humanas más comunes y sencillas. Y entonces sus apreciaciones pueden formar parte de la fabulación pero no de la Filosofía. En el caso que nos ocupa basta decir que el carácter donal del perdón no lo convierte en irracional.

Llegados a este punto, y comprobada las dificultades de un sentido secular del perdón, pareciera que debe buscarse alguna otra vía de acceso, visto que no tenemos punto de apoyo en el pensamiento ni clásico ni contemporáneo. Lo que muestra a las claras la inexistencia de una noción de perdón al margen de la que se ancla en una determinada doctrina religiosa. De ahí la incapacidad de nuestro imaginario para explicar el perdón. Porque más allá de su uso político y jurídico, parece claro que todos los occidentales lo requerimos, lo necesitamos y lo buscamos, aunque ninguno parezca saber por qué. Tal vez nadie parece saberlo porque ha aparecido en nuestra civilización de la mano de una doctrina religiosa concreta, todavía no se le ha encontrado una justificación al margen de tal doctrina y no parece que estemos en camino de alcanzarla. La capacidad de asombro no debería terminar aquí. En efecto, si se busca cómo presenta tal doctrina religiosa el perdón resulta que lo manifiesta como obligatorio siempre y en toda circunstancia. $\mathrm{Y}$ es así únicamente porque la misma divinidad lo practica y ordena que sea practicado. El extremo parece volverse escandaloso a nuestra mentalidad contemporánea cuando comprobamos que esa misma divinidad amenaza con las peores penas a quien no cumpla el mandato incondicional de perdonar, al punto que es posible que sea la víctima quien paradójicamente sufra el peor castigo.

Por todo lo anterior, cabe seguir preguntándose el por qué. Es decir, tratar de averiguar qué hay en el ser humano que no ha enviado el perdón al mueble de los objetos desechables e inservibles. Pero esta pregunta excede una vez más del propósito de estas páginas y vuelve a mostrar de nuevo la necesidad de atreverse a pensar por uno mismo en lo que realmente somos, con el riesgo que conlleva pero con la seguridad de que sólo así somos capaces de encontrar la plenitud a la que aspiramos. 
PEDRO RIVAS

\section{BIBLIOGRAFÍA}

\section{Fuentes primarias}

ARISTÓTELES, Ética a Nicómaco. Se cita por la edición bilingüe y traducción de María Araujo y Julián Marías (7. ${ }^{\mathrm{a}}$ ed.), Centro de Estudios Políticos y Constitucionales, Madrid, 1999.

Platón, Diálogos, ed. de Emilio Lledó et al., vols. I-V (incluye I: Apología, Critón; II: Gorgias; III: Fedón), Gredos, Madrid, 1981-88.

LuCio Anneo SÉnECA, De Clementia II 3, 1. Se cita por la edición bilingüe con estudio preliminar, traducción y notas de Carmen Codoñer, Tecnos, Madrid, 1988.

\section{Fuentes secundarias}

Adkins, A. W. H., Merit and Responsability. A Study in Greek Values, Clarendon Press, Oxford, 1960.

Arendt, H., The Human Condition, The University of Chicago Press, Chicago, 1958. Se emplea la traducción castellana de R. Gil Novales, La condición bumana, Paidós, Barcelona, 1993.

Bernstein, R. J., «Derrida: The Aporia of Forgiveness», Constellations 13 (2006), pp. 394-406.

Cornford, F. M., From Religion to Philosophy, Cambridge University Press, Cambridge, 1912. (Hay traducción española de A. Pérez Ramos, Ariel, Barcelona, 1984).

Cornford, F. M., Antes y después de Sócrates, Ariel, Barcelona, 1980. Traducción de la edición inglesa Before and after Socrates, Cambridge University Press, Londres, 1926.

Crespo, M., El perdón. Una investigación filosófica, Ediciones Encuentro, Madrid, 2004.

DerRIDA, J., El siglo y el perdón seguido de Fe y saber, Ediciones de la Flor, Buenos Aires, 2003.

DodDs, E. R., The Greeks and the irrational, University of California, 1955. (Hay traducción española de M. Araujo, Alianza, Madrid, 1986).

FLAMERIE DE LACHAPELlE, G., «Trois traits négatifs de la misericordia dans le second livre du De Clementia de Sénèque», Les Études Classiques, 74 (2006), pp. 309322.

Griswold, Ch. L., Forgiveness. A Philosophical Exploration, Cambridge University Press, New York, 2007.

Havelock, E. A., Preface to Plato, Basil Blackwell, Oxford, 1963.

JaEger, W., Paideia die Formung des griechischen Menschen, De Gruyter, Berlin, 19391944. (Hay traducción española en México, Fondo de Cultura Económica, 1982). 
Jankélévitch, V., Le pardon, Editions Montaigne, Paris, 1967. Hay traducción castellana de Núñez del Rincón, Seix Barral, Madrid, 1999.

- Pardonner? (1971), en L'imprescriptible, Seuil, Paris, 1986.

Janover, M., «The Limits of Forgiveness and the Ends of Politics», Fournal of Intercultural Studies, 26 (3) (2005), pp. 221-235.

Konstan, D., «Clemency as a virtue», Classical Philology, 100 (2005), pp. 337-346.

KÖNZÖL, M., «Clemency and justice in the De Clementia of Seneca», Iustum Aequum Salutare, IV (2008), pp. 61-69.

Lloyd-Jones, H., The Fustice of Zeus, University of California Press, Berkeley, 1971.

Murphy, J. G. \& Hampton, J., Forgiveness and Mercy, Cambridge University Press, Cambridge, 1988.

Nestle, W., Vom Mythos zum Logos, Scientia Verlag, Aalen, 1966.

Pettigrove, G., «Hannah Arendt and Collective Forgiving», Fournal of Social Philosophy, 37 (4) (2006), pp. 483-500.

RIvas, P., Fusticia, Comunidad, Obediencia. El pensamiento de Sócrates ante la ley, Eunsa, Pamplona, 1996.

SMith, R. W., «Redemption and Politics», Political Science Quarterly, 86 (2) (1971), pp. 205-231.

Thompson, J., «Is Apology a Sorry Affair? Derrida and the Moral Force of the Impossible», The Philosophical Forum, 41 (2010), pp. 259-274.

Verdeja, E., «Derrida and the Impossibility of Forgiveness», Contemporary Political Theory, 3 (2004), pp. 23-47. 
0000 


\section{ARTÍCULOS}

0000 
0000 